\title{
O menor infrator. Estudo comparativo do Direito Francês e do Direito Brasileiro*.
}

\author{
Martha Bohomoletz de Abreu Dallari
}

\begin{abstract}
I. Valor do estudo comparativo.
Sumário: 1. Importância dos estudos comparativos. 2. Tendências do Direito Comparado. O Direito Comparado como disciplina autônoma. 3. O Direito Comparado como método de investigação jurídica. 4. Os estudos comparativos e o Direito Penal. 5. Âmbito da comparação. 6. $O$ problema da delinqüencia juvenil perante $o$ Direito Comparado.
\end{abstract}

1. A importância dos estudos comparativos é devida à necessidade de constituirem as nações um patrimônio comum de seus recursos tanto materiais, quanto científicos e culturais.

A convivência e o mútuo respeito entre os povos determinam a aproximação de seus interêsses espirituais. Dentre as formas de colaboração intelectual destaca-se o estudo do direito estrangeiro; a comparação dos diversos sistemas legislativos contribui de forma decisiva para o desenvolvimento do direito, sobretudo apresentando soluções para a

* Trabalho apresentado à Cadeira de Direito Penal Comparado, no curso de especialização da Faculdade de Direito da U.s.P. em 1962. 
adequação progressiva das leis de cada país às constantes modificações do mundo econômico e social ${ }^{1}$.

2. A partir do I Congresso Internacional de Direito Comparado, realizado em Paris, em 1900, duas tendências, especialmente, caracterizaram a finalidade preconizada para o Direito comparado. Conforme a primeira orientação, o Direito Comparado constituiria disciplina autônoma. Segundo a outra, seria um método de investigação jurídica.

Lambert, iniciador dos estudos de Direito Comparado entre os sistemas vigentes nas Nações civilizadas, autor de Conception général, définition, méthode et histoire du Droit Comparé, apresentado no Congresso de Paris, fêz distinguir entre a comparação de direitos, ilimitada no tempo e no espaço, visando descobrir as causas que determinam a origem o desenvolvimento e a decadência das instituições jurídicas, e que denominou "história comparativa do direito", da "legislação comparada", na qual a comparação seria utilizada como técnica juridica, visando a formação de um sistema internacional de direito, a ser aplicado às nações que tivessem alcançado o mesmo grau de civilização. A esta parte, que considerava como arte, denominou também direito internacional privado ou civil ${ }^{2}$.

Para Raimond Saleilles, o Direito Comparado alcançava sua finalidade em três etapas: na primeira estudavam-se as legislações de diversos países, procurando agrupar as que apresentassem semelhanças orgânicas; na segunda, far-se-ia a crítica comparativa das instituições aí consagradas; na terceira etapa, coligidos os princípios gerais comuns aos sistemas de direito, constituir-se-ia um modêlo,

1. "Il diritto comparato rappresenta lo strumento per la formazione di un "linguaggio" giuridico internazionale. Il rafforzare e sviluppare nel diritto un linguaggio ideale, internazionalmente uniforme significa, a sua volta, contribuire ad una sempre maggiore comprensione, e perció a una sempre maggiore cooperazione internazionale" - TULLIo AsCARELLI - Studi di Diritto Comparato e in tema di interpretazione p. 5 .

2. Cf. Fonction du Droit Civil Comparé, Paris, 1903. 
que denominou "droit idéal relatif", pois tais princípios, ainda que universais, não eram imutáveis ${ }^{3}$.

3. Mais recentemente, com GuTtERIDGE, professor de Cambridge e vice-presidente do Comitê Internacional de Direito Comparado da unesco, com René David, com KadeN, e principalmente através dos Institutos de Direito Comparado, os estudos comparativos tiveram enorme desenvolvimento.

Surge então o Direito Comparado como método de investigação jurídica. $\mathrm{O}$ processo comparativo utilizado quando se pusessem em confronto as instituições jurídicas consagradas por diversas legislações, a fim de verificar suas semelhanças e divergências, não originaria, por si só, novas regras a serem aplicadas às relações humanas. Manter-se-ia a denominação "Direito Comparado" por já ter sido consagrada pela tradição.

GutTeridge, em sua obra Comparative Law - An Introduction to the Comparative Method of Legal Study and Research, publicada em 1946, fêz a distinção entre o Direito Comparado Descritivo e o Direito Comparado Aplicado. A diferença seria estabelecida atendendo-se aos fins que se pretendessem alcançar. O Direito Comparado Descritivo faria simplesmente a descrição dos sistemas de direito de um país estrangeiro, teria função informativa. Dêste tipo seriam os estudos preparatórios à execução de um plano para a unificação do direito e também uma simples compilação dos sistemas de direito estrangeiro. Nos estudos de Direito Comparado Aplicado é feita uma análise dos sistemas a fim de verificar suas semelhanças e divergências. Posteriormente faz-se uma síntese com base nos resultados obtidos pelo processo analítico, a fim de atender a uma finalidade imediata, que pode ser exclusivamente científica ou ter caráter prático. Científica, quando se pretende estabelecer quais os principios que se acham na base dos sis-

3. Cf. Conception et Objet de la Science du Droit Comparé, in "Traité de Droit Comparé" — Arminjon-Nold-Wolff. 
temas jurídicos do mundo civilizado ou então quando se estuda a evolução de certa instituição jurídica em diversos sistemas a fim de traçar a evolução histórica dessa mesma instituição em outro sistema legislativo. Através da finalidade prática, procura-se a reforma do direito vigente ou a unificação de legislações distintas.

Considerando-se o Direito Comparado como método, sua característica principal é ser aplicável a todos os âmbitos da indagação jurídica.

4. A aplicação dos estudos comparativos à solução dos problemas que surgem da regulamentação da conduta humana no campo do ilícito penal parece extremamente complicada quando consideramos que, mesmo nos países em que o nível de civilização é o mesmo, a diversidade da cultura, da tradição, dos costumes, assim como da estrutura das instituições jurídicas, constitui um obstáculo para a idêntica incriminação das condutas delituosas, e a determinação das penas a serem aplicadas.

No campo da prevenção à criminalidade, contudo, os estudos comparativos têm sido o melhor meio para se verificar se as medidas adotadas em determinado país e destinadas ao combate de algumas modalidades delituosas têm sido eficazes.

Para reforma do direito vigente são imprescindíveis a investigação e a comparação com outros sistemas legislativos. Facilitando a função do legislador, o trabalho de pesquisa em outras legislações, feito pelo jurista, contribui com elementos valiosos para o aperfeiçoamento do direito.

$\dot{E}$ preciso que as reformas da lei sejam cuidadosamente elaboradas, para que se possa verificar quais as medidas, já declaradas em textos estrangeiros, cuja promulgação traria real proveito no sistema legislativo que as viesse consagrar.

E inegável a vantagem que traz o estudo comparativo, que possibilita ao jurista o conhecimento, a compreensão dos dispositivos estrangeiros e a adequação à lei de seu país. 
5. No âmbito de uma comparação entre as legislações penais, é preciso indagar da conveniência de apreciar sòmente dois ou então diversos sistemas jurídicos; além disso, se é melhor comparar o sistema tomado em conjunto ou apenas um conceito legal. É preciso encontrar também os textos legais que servirão à comparação, que devem conter o direito vigente. Importa também verificar a jurisprudência e a doutrina dos autores como elementos importantes para a exata compreensão dos dispositivos legais.

O valor da comparação não depende do número de sistemas estudados. Não apresentaria vantagem a enumeração de tôdas as diferenças jurídicas existentes entre dois ou mais sistemas. O limite do estudo comparativo deve ser estabelecido pelo encontro dos principios informativos dos sistemas que se estudam.

6. A questão da delinqüência juvenil é, no campo penal, um dos mais importantes problemas da atualidade.

Fruto do desajustamento social, da desorganização familiar e, muitas vêzes, vítima da situação econômica, o menor delinqüente viu convergirem sôbre si as atenções dos sociólogos, juristas e educadores, que procuraram, no campo de suas especialidades, prevenir os males decorrentes do transviamento juvenil.

No Brasil, a legislação referente aos menores está para ser revista. Os estudos relativos às reformas propostas tornam-se muito oportunos. Entre êles, os comparativos revelam as disposições modelares cuja promulgação pode ser aconselhada a todos os países como o meio mais adequado para se alcançar o ideal da Justiça penal. Muito útil nos será verificar as soluções dadas ao problema no sistema de direito francês.

Na orientação francêsa, o movimento de "reclassificação social" está dispensando aos "pré-adultos" delinqüentes o tratamento especial que favorece os menores de vinte e um anos. No campo das realizações práticas, foram orga- 
nizados para adultos jovens, até vinte e cinco anos, "prisões escolas" em Oermingen e Toul.

\section{O menor delinqüente na França e no Brasil.}

SUMÁRIo: 1. Conceituação do menor delinqüente no Direito Francês: a) As medidas de proteção ao menor infrator. b) $O$ discernimento como critério de impntabilidade. c) Modificação do critério do discernimento. 2. Conceituação do menor delinqüente no Direito Brasileiro: a) $O$ menor delinqüente no Código Criminal do Império. O discernimento. b) $O$ menor delinqüente perante o Código Penal de 1890. c) O Código de Menores. 3. Tratamento legislativo do problema: a) Na França. b) No Brasil. c) Conseqüencia da orientação adotada - o coF.

1. a) Em matéria penal, a proteção jurídica dos menores, que, em virtude de sua idade, de sua inexperiência, de sua incapacidade de compreender ou agir, merecem maior atenção da sociedade, foi uma conquista definitiva da lei francêsa de 22 de Julho de 1912, consagrando as idéias de defêsa social e aplicando ao menor infrator as medidas de proteção, de assistência, de vigilância ou reforma que parecessem necessária ${ }^{4}$.

A ordenança de 2 de Fevereiro de 1945 continuou a evolução iniciada pela lei de 1912 e assim a pena, de maneira geral, foi substituída por medidas de proteção, que variam, sendo individualizadas segundo as circunstâncias da causa e a personalidade do menor infrator.

b) Na França, desde o Código Penal de 1791 obra da Revolução, a questão da irresponsabilidade penal do menor de 16 anos estava ligada à do discernimento.

O Juiz, ao examinar a infração praticada pelo menor, verificava se tinha êste agido com discernimento. Em caso

4. Cf. Marc Ancer, In Révue de Science Criminelle et Droit Pénal Comparé, p. 563, vol. Iv, 1947. 
afirmativo, condenava-o a uma pena, quase sempre curta, de detenção, que era cumprida em Casa de Correção. Em caso negativo, absolvia-o e determinava que fôsse entregue à própria família. Se isso não fôsse possivel, o menor deveria ser internado na Casa de Correção, para aí ser educado, por um períndo que não poderia ultrapassar o seu vigésimo aniversário.

Este sistema foi mantido pelo Código Penal de 1810. Contudo, ao aplicar a lei os juízes preferiam considerar o menor como tendo agido com discernimento. Então abrandavam a pena, com a atenuante da menoridade, e o menor ficava pouco tempo na Casa de Correção.

Outrossim, apesar de absolvido, o menor infrator, que não tinha para onde ir, era internado até os 20 anos na mesma Casa de Correção, onde também se encontravam adultos criminosos 5 .

c) A Lei de 5 de Agôsto de 1850, que criava as Colônias Penitenciárias, alterou esta situação. A noção de discernimento passou a não mais ser considerada pelos juízes como um fim em si, não mais se procurava saber se o menor era capaz de distinguir entre o bem e o mal ou então compreender o caráter ilegal da infração. $O$ critério do discernimento foi aceito como meio prático para se tomar uma decisão em função da medida a ser aplicada. $O$ envio à Colônia Penitenciária foi preferido ao regime de penas curtas de privação da liberdade.

Pela Lei de 12 de Abril de 1906 o limite da responsabilidade penal foi fixado em 18 anos.

Com a Lei de 1912 a questão da responsabilidade começou a se desvincular da questão do discernimento. Para os menores de 13 anos estabeleceu-se a presunção absoluta de irresponsabilidade; entre os 13 e os 18 anos foi mantido o critério do discernimento, não observado, contudo, na prática.

5. Cf. Jean Pinatel, Traité Elementaire de Science Pénittentiaire e de défense Sociale, p. 414. 
Com a ordenança de 1945 foi definitivamente abolida a questão do discernimento como critério para responsabilizar o menor pela prática de infração penal.

2. a) Ao tempo da promulgação do Código Penal do Império não se cogitava de um sistema especial de proteção ao menor infrator, no Brasil. As penas aplicadas eram cumpridas nas Casas de Correção, onde nem ao menos se separavam os delinqüentes menores dos adultos. Para aplicação ou não da penalidade, o Juiz verificava a capacidade de discernimento do menor. Como regra geral, o Código preceituava em seu artigo $3 .^{\circ}$ : Não haverá criminoso ou delinqüente sem má fé, isso é, sem conhecimento do mal e intenção de o praticar".

0 artigo 10 dispunha: "Também não se julgarão criminosos: $\S 10^{\circ}$ - Os menores de 14 anos".

0 artigo 13, como exceção ao artigo 10 , preceituava: "Se se provar que os menores de 14 anos, que tiverem cometido crime, obraram com discernimento, deverão ser recolhidos às Casas de Correção, pelo tempo que o Juiz parecer, contanto que o recolhimento não exceda à idade de 17 anos".

Assim o critério do discernimento estabelecia a possibilidade da imposição da pena. Sua verificação ficava sob o encargo do Juiz, a quem incumbia decidir da sorte e do destino do menor até os 17 anos.

A circunstância de o infrator ser menor de 21 anos era considerada sempre atenuante (artigo 18, § 10). Ao menor entre 14 e 17 anos o Juiz poderia aplicar as penas da cumplicidade ao invés das do crime (artigo 18, $\S 10$, "in fine").

Também aos menores de 21 anos não se impunham as penas de galés, que seriam substituídas pelas penas de prisão com trabalho por igual tempo (artigo $45, \S 2 .^{\circ}$ )

Em uma apreciação geral da situação do menor infrator perante o Código criminal do Império, verifica-se que a idade de 14 anos estabelecia o limite para se verificar se o menor praticara a infração com ou sem discernimento, a 
fim de, em caso afirmativo, aplicar-lhe uma pena que não poderia ultrapassar a sua idade de 17 anos.

Ao maior de 14 anos seriam aplicadas as penas cominadas para a infração, com a atenuante da menoridade. Ao menor entre 14 e 17 anos o Juiz poderia aplicar as penas de cumplicidade, que eram as do crime reduzidas da têrça parte em cada um dos graus (artigos 34 e 35$)^{6}$.

b) O Código Penal de 1890 cuidou da situação dos menores infratores em seus artigos 27 e 30 .

Dispunha o artigo 27: "Não são criminosos: $\S 10^{\circ}$ os menores de 9 anos completos; $\S 2 .^{\circ}$ os maiores de 9 anos e menores de 14 que obrarem sem discernimento".

$\mathrm{O}$ artigo 30 determinava que se recolhessem os maiores de 9 anos e menores de 14, que tivessem agido com discernimento, a estabelecimentos disciplinares e industriais.

Acolhia assim o novo Código o critério do discernimento com o fim de aplicar ao menor a pena de recolhimento a estabelecimentos especiais. No dizer de Cândido Motta os demais menores infratores - os que tivessem agido sem discernimento, sendo legalmente irresponsáveis, "escapavam à ação do Poder Punitivo Social"”.

Quanto aos infratores com mais de 14 anos, assim dispunha o artigo 65: "Quando o delinqüente fôr maior de 14 anos e menor de 17, o Juiz lhe aplicará as penas de cumplicidade".

$\mathrm{O}$ artigo 64 dispunha que a cumplicidade seria punida com as penas da tentativa e o artigo 63 que a tentativa a que não estivesse imposta pena especial seria punida com as penas do crime menos a terça parte, em cada um dos graus ${ }^{8}$.

6. Cf. Paula Pessoa, Código Criminal do Império do Brasil, Nota 55 , p. 41 ; Nota 123 , p. 68.

7. Cf. CÂNdido N. Nogutira dA MotTA, Os menores delinqüentes e o seu tratamento no Estado de São Paulo, p. 89.

8. Cf. Lemos Brito, As leis de menores do Brasil, p. 96. 
c) Essa foi a situação que perdurou até o Decreto n. 16.272, de 20 de Dezembro de 1923, que tratou de um regulamento da assistência e proteção aos menores abandonados e delinqüentes. Pelo Decreto $n .^{\circ} 5.083$, de $1 .^{\circ}$ de Dezembro de 1926 ficou o Poder Executivo autorizado a consolidar as leis de assistência e proteção aos menores. Em virtude dessa autorização, o Decreto 17.943-A surgiu como Código de Menores.

O Capítulo vil do Código de Menores foi dedicado aos menores delinqüentes. O pensamento dos autores da lei brasileira foi banir do Código a idéia de pena. Assim, o "menor de 14 anos, indigitado autor ou cúmplice de fato qualificado crỉme ou contravenção, não será submetido a processo penal de espécie alguma" (artigo 68). Tratando-se de menor de 14 a 18 anos, seria submetido a processo especial (artigo 69). Se o crime praticado pelo menor fôsse considerado grave e o infrator revelasse extrema periculosidade, seria enviado a um estabelecimento para menores infratores ou ficaria em uma sessão especial da prisão comum, separado completamente dos adultos, até que se verificasse sua regeneração a fim de cumprir a pena prevista para a infração praticada, com a redução de um têrço, segundo o que dispunha o artigo 65 do Código Penal de 1890. (Posteriormente, a Lei de Introdução do Código Penal alterou, por seu artigo $7 .^{\circ}$, esta disposição). Importante modificação foi trazida com a abolição pelo Codigo do critério do discernimento 9 .

9. A orientação adotada pelos Código Penais anteriores tinha sempre provocado debates. LEMOs BRITo reproduz a controvérsia defendendo a nova orientação: "Que se deve entender por discernimento? $\mathrm{Na}$ interpretação usual dos juristas, êle consiste em saber que determinado ato é legalmente punível. E, todavia, conforme pondera TOULEMoN (Le progrés des institutions pénales) ao invés de indagar do menor - Sabíeis perfeitamente que isto era proibido? - o Juiz deveria perguntar ao perito: - Diante de tudo que conheceis do menor, acreditais que êle podia resistir à injunção criminal a que acaba de obedecer?

Pois é precisamente o que o nosso Código faz (ob. cit., p. 130). 
Foi adotado um critério científico. Estabeleceu-se o limite de 18 anos, dentro do qual o Juiz, de acôrdo com as informações a respeito tanto da personalidade do menor quanto de seu ambiente, pronunciaria as medidas de proteção, quer de reeducação quer de tratamento que parecessem mais convenientes ao caso.

3. Tratamento legislativo do problema.

a) $\mathrm{Na}$ França.

A Ordenança . $^{\circ} 14.174$, de 2 de Fevereiro de 1945 , relativa à infância delinqüente, foi modificada, em diversos artigos, por novas disposições. Assim, desde $1 .^{\circ}$ de Outubro de 1959, com uma ampliação que entrou em vigor a $10^{\circ}$ de Janeiro de 1960 , vem sendo aplicada a Ordenança $n .^{\circ} 58.130$, de 23 de Dezembro de 1958.

Estes textos dão, no âmbito de cada Departamento (Circunscrição administrativa), ao "Directeur de La Population et de l'Aide Social, e ao "Juge d'Enfants", poderes extensos em matéria de prevenção. Êles exercem uma "assistência educativa" (em casos extremos até mesmo sem autorização dos pais), junto a todos os jovens de menos de 21 anos "cuja saúde, segurança, moralidade ou educação se achem comprometidas".

Como regra geral, o "Tribunal Pour Enfants" e a "Cour d'Assises des Mineurs" pronunciarão, com relação ao menor infrator, as medidas de proteção, de assistência, de vigilância e educação que se evidenciarem necessárias (artigo 2. ${ }^{\circ}$, Ord. 24-v-1951) ${ }^{10}$.

10. Há um Tribunal "Pour Enfants" em cada Departamento. E presidido pelo Juiz de Menores, assistido por dois assessôres, escolhidos dentre as pessoas que se distinguiram pelo seu interêsse pelos problemas da infância. Seu estatuto foi regulado pelo Decreto de 18 de Julho de 1945, completado pela Ord. de 23-XII-1958 (cf. Pinatel, ob. cit., p. 422).

A “Cour d'Assises des Mineurs" é formado pelo Presidente, por dois assessôres, de preferência Juízes de Menores, e pelo Juri Criminal, compôsto de nove membros (art. 20, Ord. 24-v-51). 
Serão competentes, quanto à apreciação dos fatos considerados infrações penais praticados pelo menor de 18 anos, o Tribunal "pour Enfants" quanto aos delitos (constituem delitos, entre outros, o furto, a fraude, as lesões corporais, - ultraje público ao pudor) e a "Cour d'Assises des Mineurs" quanto aos crimes (constituem crimes, entre outros, o roubo com circunstâncias agravantes, o homicídio, a tentativa de homicídio, o incêndio voluntário, o estupro, o atentado contra o pudor).

Aos maiores de 13 anos podem ser aplicadas condenações penais (art. 18 - Ord. 2-II-1945). Há, então, duas situações: a do menor entre 13 e 16 anos e a do menor com mais de 16 anos. Em ambos os casos as condenações serão pronunciadas se a personalidade do menor e as circunstâncias o exigirem ${ }^{11}$. As decisões dêsse tipo deverão ser pormenorizadamente fundamentadas, sob pena de nulidade.

Havendo condenação penal, a atenuante da menoridade será aplicada obrigatòriamente se o menor estiver entre 13 e 16 anos. Será facultativa se se tratar de menor com mais de 16 anos. Isso em virtude do dispôsto na parte introdutória ao Código Penal, que trata "Des personnes punissables, excusables ou responsables pour crimes ou pour délits". A circunstância atenuante opera determinando a redução da pena de acôrdo com a gravidade e o quantum daquela cominada para a infração.

$\mathrm{Na}$ maioria dos casos têm sido impostas aos menores medidas educativas ${ }^{12}$, que, além de tôdas as outras vantagens, não deixam traço algum no seu prontuário.

11. Para alguns autores, entre êles DonnedieU DE VABREs, o têrmo "circunstâncias" significa "razões variadas de política criminal". Para outros equivale, simplesmente, às circunstâncias do delito.

12. Em 1956, entre 14.778 julgamentos referentes a menores, houve 1.843 condenações $(9,5 \%)$, a saber: 921 penas de prisão com "sursis"; 285 penas de prisão sem "sursis"; 223 penas de multa e prisão com "sursis"; 414 penas de multa e prisão sem "sursis".

Da 285 penas de prisão sem "sursis", 161 tiveram duração inferior a 4 mêses, 55 entre 4 mêses e 1 ano, 39 de mais de 1 ano. 
A Ordenança de 23 de Dezembro de 1958, alargando as atribuições dos Juízes especializados, estendeu a proteção judicial a todos os casos em que "a saúde, a segurança, a moralidade ou a educação de um menor de 21 anos se encontrarem comprometidas". Considerando-se que um jovem delinqüente está incontestàvelmente em perigo, os juízes podem esquecer a infração para só aplicar uma medida de "assistência educativa".

A razão principal de ainda se aplicar a medida repressiva a menores é o poder de intimidação contra a reincidência que essa penalidade exerce. Em muitos casos, efetivamente, pouco vale o internamento em uma instituição especializada, pois para muitos jovens o cumprimento de uma pena curta de prisão tem maior eficácia do que uma longa estadia por tempo inderminado, até provàvelmente o seu 21. ${ }^{\circ}$ aniversário, em um Centro de Reeducação.

A prisão do menor infrator será cumprida em lugares e condições especialmente previstos em regulamento especial da Administração Pública.

b) No Brasil.

O Decreto-Lei n. ${ }^{\circ}$ 6.026, de 24 de Novembro de 1943, dispõe sôbre as medidas aplicáveis aos menores de 18 anos pela prática de fatos considerados infrações penais. Fêz-se necessária a elaboração dêsse decreto em virtude do dispôsto no artigo 23 do Código Penal de 1940: "Os menores de 18 anos são penalmente irresponsáveis, ficando sujeitos às normas estabelecidas na legislação especial". Há duas situações: a do menor de 14 a 18 anos, a que o Juiz, após verifícar as circunstâncias e os motivos do fato criminoso e as condições do menor e sua periculosidade, aplicará as medidas de assistência que forem necessárias, compreendendo até a internação em estabelecimento especial e mesmo em secção especial da prisão destinada a adultos (art. $2^{\circ}$, letras " $a$ " e "b", e $\S 10^{\circ}$ ), em casos de extrema periculosidade do menor. Êsse internamento poderá durar até os 21 anos. Se até lá não houver cessação da periculosidade, o infrator 
será transferido para Colônia Agrícola ou para Instituto de Trabalho, de Reeducação ou de Ensino Profissional, destinado ao cumprimento de medidas de segurança aplicáveis a adultos, ou para secção especial de outros estabelecimentos (art. 7. $.^{\circ} \S 2 .^{\circ}$ da Lei de Introdução do Código Penal).

Se o menor contar menos de 14 anos, o Juiz "adotará as medidas de assistência e proteção indicadas pelos motivos e circunstâncias do fato e pelas condições do menor" $\left(\right.$ art. $\left.3 .^{\circ}\right)$.

Assim, no direito brasileiro, o menor de 18 anos é ininputável, não lhe podendo ser aplicada pena, mas sòmente medidas de proteção, assistência e disciplinares, de acôrdo com a sua personalidade, para que se torne possível a individualização do tratamento. - O "coF".

c) Conseqüência da Orientação Adotada no Brasil

Subordinado diretamente ao Juizado de Menores da Capital de São Paulo, o Centro de Observação Feminina (cof) destina-se a abrigar menores do sexo feminino acusadas da prática de fatos considerados infrações penais, até que seja estabelecida a sua situação definitiva.

O coF corresponde ao recolhimento provisório de menores (RPM) criado pela Lei 2.705, de 23 de Julho de 1954, destinado a menores do sexo masculino.

$\mathrm{O}$ artigo $2 .^{\circ}$ dessa lei consagra disposições especiais relativas à informação, ao exame médico e à pesquisa social necessários para se conhecer a verdadeira personalidade do menor e sua situação no meio ambiente.

Cumprindo tais disposições, faz-se no coF um estudo de cada caso. O tempo necessário para isso é, em regra, o de três meses. Essse estudo, feito por uma equipe especializada, composta de médica, psicóloga, advogada e assistente social, é encaminhado ao Curador de Menores e depois ao Juiz de Menores, para que seja proferida a decisão definitiva.

Após a identificação da menor e a indicação de sua filiação, é elaborado o estudo em três partes: a) Estudo social: 1. antecedentes do caso; 2. levantamento sócio-fa- 
miliar; 3. verificação do comportamento da menor em casa. b) Estudo jurídico: 1. registro civil da menor: 2. verificação da prática de qualquer infração, anteriormente; 3. indicação da existência de qualquer processo já instaurado. c) estudo das condições fisicas e mentais da menor: A 1 . exame clínico geral; 2 . exame ginecológico; 3 . exame odontológico; в 1. exame psico-pedagógico; 2 . exame psiquiátrico.

As conclusões sôbre cada caso são elaboradas em conjunto pela equipe, em reuniões realizadas semanalmente. Concluindo, é feita uma sugestão para uma solução definitiva a ser dada pelo Juiz.

O Juiz pode entregar a menor à própria família ou a quem assuma a sua guarda ou então interná-la em estabeJecimento de reeducação. Em nosso Estado, o Serviço Social de Menores mantém convênio com os seguintes estabelecimentos: Colégio Bom Pastor, Mansão Sagrado Coração de Jesus, Mansão Sagrado Coração de Maria, os três sob a direção de religiosas, e o Instituto Modêlo de Campinas, leigo. Nesses institutos as menores receberão o tratamento adequado, visando sua reeducação.

O COF, que funciona, portanto, como Casa de Triagem, tem, em média, 50 menores. Elas se dividem em quatro grupos, conforme o grau de inteligência e a escolaridade, de cada grupo, exigindo-se uma série de atividades, programadas cada dia.

Para o cor vão as meninas de 14 a 18 anos, encaminhadas pela Polícia, pelo Comissariado de Menores, ou pelo próprio Juizado de Menores. (Dentre as atribuições do Juiz de Menores encontra-se a de "ordenar de plano a apreensão e a internação de menores abandonados e infratores, pervertidos ou em perigo de se perventerem; e a instauração dos processos respectivos" - art. $2 .^{\circ}, \S 14$, Lei 495 , de 28-10-1949).

Nos dois anos em que já vem funcionando, o coF fêz um levantamento para se saber quais as infrações ou irregularidades de conduta mais praticadas pelas menores entre 14 
e 18 anos que para lá eram levadas. Em 165 menores, $80 \%$ praticavam a prostituição; em grande parte dos casos essa prática vinha acompanhada de infrações, em ordem decrescente: furto $(26 \%$ em $80 \%)$; furto e desordem $(6 \%$ em 80\%); uso de entorpecentes; assalto (conto do suadouro); agressão; desordens (em porcentagem inferior a $5 \%$ de $80 \%$ cada uma das infrações por último enumeradas).

Em segundo lugar aparecia o furto, $10 \%$ dos casos. Em seguida, entre os 165 casos havia: 8 de desordem, 6 de alcoolismo, 3 de co-autoria em homicídio e 1 de infanticídio.

Oito menores para lá foram encaminhadas por se encontrarem em estado de abandono e oito por terem fugido de casa.

O grande obstáculo a um alcance maior do trabalho que o CoF vem executando é a maioridade penal das que completam 18 anos no COF e fogem à jurisdição do Juiz de Menores.

É freqüente serem encaminhadas ao COF menores com quase 18 anos; a instauração de processo obriga a que se inicie o relatório, terminado êste e determinado pelo Juiz o internamento da menor, não pode ser cumprido em virtude de a menor já ter completado os 18 anos.

Maior dificuldade surge ainda quando a menor não tem para onde ir, pois os pensionatos com os quais o Serviço Social do Estado mantém convênio não têm vagas.

Seria justo e razoável que as medidas decretadas pelo Juiz pudessem ser cumpridas além dos 18 anos em um prazo que não se estenderia além dos 21 anos. Tal situação já se verifica nos casos em que o menor revela extrema periculosidade e necessita ficar desligado do convívio social. Êsses casos são, contudo, raros, e a medida tem caráter excepcional.

o relatório elaborado pelo cof, que serve para informar o Juiz sôbre a personalidade da menor e sôbre seu meio-ambiente, orienta-o na escolha da melhor medida para reeducação e proteção do menor cuja situação de infra- 
tor revela a necessidade de um tratamento adequado. Para que dê resultados, é preciso que a medida seja cumprida. Para isso não pode ser obstáculo a maioridade penal.

\section{Conclusão.}

SUMÁRIO: 1. Variação das legislações segundo as doutrinas dominantes. 2. A adoção de medidas tutelares. 3. Contribuição do estudo comparativo para o Direito Brasileiro.

1. O direito repressivo consagrou um tratamento especial para as crianças e jovens.

O critério para o estabelecimento da responsabilidade do menor variou do Código Penal da Revolução Francêsa às leis de nossos dias, segundo as diversas tendências que assinalaram o desenvolvimento do Direito Penal.

$\mathrm{O}$ discernimento atendia à necessidade da verificação do pleno desenvolvimento psíquico do menor. A responsabilidade penal estava fundada na capacidade de escolha entre os motivos que levavam a agir. Constantando-se a exata compreensão, por parte do menor, do caráter ilícito da ação praticada, era permitida a aplicação da pena.

O abrandamento de sistema tão drástico foi obra dos juízes. Na França, pela verificação automática do discernimento o juiz passou a escolher a medida a ser aplicada ao menor, procurando o seu maior benefício.

No princípio dêste século, a propósito do discernimento, assim se exprimia CÂNDIDo MotTa: "A questão do discernimento não pode ser pràticamente resolvida sem um estudo longo e acurado de cada menor, da sua psicologia, do grau de desenvolvimento de sua inteligência, para o que os nossos juízes, com o atual sistema processual, não têm a necessária competência, pois não é crivel que êles em duas ou três audiências, nas quais o menor só é ouvido num lacônico interrogatório, peça de defêsa, em que é livre 
de falar ou não falar, possam conhecê-lo suficientemente para aplicar a lei"13.

A prática judiciária evidenciou as falhas do discernimento como critério para a responsabilidade penal. Modificaram-se então as legislações de menores, a francêsa em 1912, a brasileira a partir de 1923, sob o influxo das doutrinas que tinham por base a defêsa social. Segundo tais sistemas doutrinários, a responsabilidade seria considerada em sentido puramente objetivo, as medidas de defêsa não teriam caráter repressivo, pois que sua aplicação não se fundaria na existência de culpa. Como conseqüência foi abolido o critério do discernimento (eliminado completamente pela lei francêsa sòmente em 1945) e fixado em 18 anos o limite da responsabilidade penal.

2. Determinando a lei que o menor de 18 anos é inimputável ${ }^{14}$, ser-lhe-á dispensado um tratamento especial, pois que, fundada a pena na existência de culpa, se torna absurdo impor a conseqüência jurídica do delito ao que é incapaz de compreender o conteúdo das exigências jurídicas e de comportar-se de acôrdo com elas.

o sistema da lei brasileira sôbre menores consagrou medidas tutelares, a serem impostas aos infratores; enquanto a lei francêsa utilizou medidas educativas e repressivas. Ainda que permitidas pela legislação francêsa, as medidas punitivas são muito pouco usadas. Os tribunais de menores só lançam mão delas quando parece ser êsse o melhor meio de conduzir o menor ao bom caminho, dado o poder intimidativo que exercem. Acredita-se que a marca que representa uma condenação penal no passado influi

13. Ob. cit., p. 88.

14. A imputabilidade pode conceituar-se como a aptidão do indivíduo para praticar determinados atos com discernimento. Responsabilidade não se considera como sinônimo de imputabilidade e sim, mais precisamente, como uma decorrência da imputabilidade. (Cf. BAsIleU GARCIA, ob. cit., p. 324). 
sôbre a conduta do delinqüente primário, fazendo com que evite a reincidência.

3. A mais importante contribuição que o estudo da legislação francêsa sôbre a juventude delinqüente traz é o conhecimento da extensão, no tempo, das medidas tutelares aos infratores entre os 18 e 21 anos, que, a critério do Juiz de Menores, se possam considerar em perigo. 0 limite dos 18 anos para a imputabilidade penal não é rígido. Caberá ao juiz verificar se a imposição de medidas educativas ao que tenha mais de 18 anos servirá para reabilitá-lo ou se plenamente imputável pelo seu ato deve ser julgado, recebendo a pena ou a absolvição. O sistema da lei brasileira, estatuindo um critério absoluto, impede mesmo que as medidas educativas impostas ao menor sejam cumpridas além dos 18 anos.

Visando resultado mais imediato, uma alteração, permitindo a continuidade do tratamento após os 18 anos, até que se obtivesse o resultado pretendido, fixado o limite máximo de 21 anos, seria de grande alcance, ampliando consideràvelmente o volume dos resultados práticos.

\section{Bibliografia.}

ALvarenga NeTto, Código de Menores - Doutrina, Legislação e Jurisprudência, Rio, 1941.

Basileu Garcla, Instituições de Direito Penal, Vol. I, São Paulo, 1956.

CÂNdmo N. NoGUEIRA dA MotTA, Os menores Delinqüentes e o Seu Tratamento no Estado de São Paulo, São Paulo, 1909.

henri Joubrel, Juventude em Perigo, Trad. de Valeriano DE Oliveira, São Paulo, 1961.

Jean Pinater, Traité Élémentaira de Science Pénitenciaire et de Défense Sociale, Melun, 1950.

JoÃo Vieira de Araújo, Nova Edição Oficial do Código Criminal Brasileiro de 1830, Anteprojeto Elaborado em 1889, Rio, 1910.

Lemos Britto, As Leis de Menores no Brasil, Páginas de Critica e de Doutrina, Rio, 1929. 
NoÉ AzEvedo, A Socialização do Direito Penal e o Tratamento de Menores Delinqüentes e Abandonados, São Paulo, 1927.

ODETE FILIPon, La Jeunesse Coupable Vous Acuse, Paris, 1950.

Sebastian Soler, Anteproyecto de Código Penal, Edición Oficial, Buenos Aires, 1960.

TUllio Ascarell, Studii di Diritto Comparato $e$ in Tema di Interpretazione, Milão, 1952.

V. A. De Paula Pessoa, Código Criminal do Império do Brasil Anotado, Rio, 1887.

\section{Codificações.}

Código de Menores, Organização, Indices e Notas de FrRnando H. Mendes DE Almeida, São Paulo, 1960.

A Lei Tutelar do Menor, Coletânea Organizada por SÉrgio MUNIZ DE SOUzA, Rio, 1958.

Code Penal, Ediation du Journal Officiel de la République Française, Paris, 1959. 